\title{
Systematic Review \\ Free-Living Dietary Intake in Tactical Personnel and Implications for Nutrition Practice: A Systematic Review
}

\author{
Kristen L. MacKenzie-Shalders ${ }^{1, *}\left(\mathbb{C}\right.$, Angela V. Tsoi ${ }^{1}$, Ka Wing Lee ${ }^{1}$, Charlene Wright ${ }^{1,2} \oplus$, Gregory R. Cox ${ }^{1}$ and \\ Robin M. Orr ${ }^{3}$ \\ 1 Nutrition and Dietetics, Faculty of Health Sciences and Medicine, Bond University, Robina 4226, Australia; \\ angela.tsoi@student.bond.edu.au (A.V.T.); kawing.lee@student.bond.edu.au (K.W.L.); \\ charlene.wright@griffithuni.edu.au (C.W.); gcox@bond.edu.au (G.R.C.) \\ 2 School of Medicine and Dentistry, Centre of Applied Health Economics and Menzies Health Institute \\ Queensland, Griffith University, Gold Coast 4222, Australia \\ 3 Tactical Research Unit, Bond University, Robina 4226, Australia; rorr@bond.edu.au \\ * Correspondence: kmackenz@bond.edu.au; Tel.: +61-755951018
}

check for updates

Citation: MacKenzie-Shalders, K.L.; Tsoi, A.V.; Lee, K.W.; Wright, C.; Cox, G.R.; Orr, R.M. Free-Living Dietary Intake in Tactical Personnel and Implications for Nutrition Practice: A Systematic Review. Nutrients 2021, 13, 3502. https://doi.org/10.3390/ nu13103502

Academic Editors: Javier Sanz-Valero and Jose Lara

Received: 9 September 2021

Accepted: 30 September 2021

Published: 3 October 2021

Publisher's Note: MDPI stays neutral with regard to jurisdictional claims in published maps and institutional affiliations.

Copyright: (c) 2021 by the authors. Licensee MDPI, Basel, Switzerland. This article is an open access article distributed under the terms and conditions of the Creative Commons Attribution (CC BY) license (https:// creativecommons.org/licenses/by/ $4.0 /)$.

\begin{abstract}
Tactical personnel (including military, law enforcement, and fire and rescue) are responsible for ensuring national and public safety. Dietary intake is an important consideration to support optimal health and performance. The aims of this systematic review were to: (1) describe the reported free-living dietary intake (energy and macronutrients) of tactical personnel, and (2) describe the practical implications of reported dietary intakes to support the physical and dietary requirements of tactical personnel. A systematic search of databases (MEDLINE, EMBASE, CINAHL and Web of Science) was conducted following the PRISMA guidelines. English and full text research articles were identified and screened against inclusion and exclusion criteria. Demographic and dietary intake data were extracted, tabulated, and synthesized narratively. The quality of the studies was assessed using the Academy of Nutrition and Dietetics Quality Criteria Checklist. Twenty-two studies (15 military, 4 law enforcement, and 2 fire and rescue) were eligible to inform this review. The volume of evidence suggested that tactical personnel met dietary protein and exceeded dietary fat recommendations but failed to meet energy and carbohydrate recommendations. Therefore, practical approaches to support optimized energy, fat and carbohydrate intake in tactical personnel is important.
\end{abstract}

Keywords: diet; nutrition; health; performance; occupation; police; fire; military

\section{Introduction}

Optimizing dietary recommendations, and subsequent intake, to support health, well-being and performance is important for tactical personnel [1]. Tactical occupations, including military, law enforcement, and fire and rescue emergency services (SES) [2], have many important dietary considerations and challenges. Several studies have reported sedentary behaviors, chronic disease risk, and obesity rates similar to, or higher than, those seen at a population level [3-11]. However, tactical occupations present a range of shared and unique challenges that can impact dietary intake [12]. Physically and mentally demanding occupational tasks [13]; heightened periods of physical exertion [14]; over-time, shift work and lack of structured breaks; working in extreme conditions (extreme heat, altitude, and low humidity) [15,16]; and specific occupational risks serve as examples $[17,18]$. Many of these factors, including long working hours, shift work, and job strain (in males) have been associated with poor diet quality [19], in turn having implications for the health, well-being, and performance capability of tactical occupations.

While a focus on nutrition strategies that promote good health are important, and population-specific recommendations can be applied, dietary recommendations to optimize macronutrient intake, and general nutrition, for performance are also warranted [20]. Tactical personnel should also maintain a requisite level of physical fitness to perform 
job tasks optimally and therefore sometimes sports nutrition recommendation are also applied $[21,22]$. Tailored dietary recommendations that provide an appropriate energy and macronutrient intake will support physical fitness [23] and likely optimize the performance of tactical personnel. A recent cross-sectional study reported that law enforcement personnel place high importance on consuming nutritious food, food high in vitamins and minerals, and that have a high protein content [20]. To the authors knowledge, several other studies have documented tactical personnel's' free-living dietary intake [15,19,24-27]. However, synthesizing current evidence to inform macronutrient requirements and broader nutrition strategies for tactical occupations would be beneficial.

Several studies have previously demonstrated that healthy eating interventions can positively impact dietary intake and behaviors in tactical personnel $[14,28,29]$. Therefore, to best support valid nutrition strategies for tactical occupations, documenting and interpreting their dietary intake and contextualizing their intake in consideration of their dietary requirements is a required initial step to inform recommendations. In the public or scientific domain, there are no comprehensive, up-to-date dietary guidelines specific for tactical occupations. While there are military dietary reference intakes (MDRIs) which are based on the recommended daily allowances (RDAs) — for military personnel which are the nutrient standards intended to meet the requirements of majority of healthy Americans aged $\geq 2$ years [30,31] — the MDRIs are approximately 20 years old and the RDAs have since been updated.

There is no known systematic review exploring dietary intake specific for tactical occupations. Therefore, the aims of this systematic review were to: (1) describe the reported free-living dietary intake (energy and macronutrients) of tactical personnel including military, law enforcement, and fire and rescue, and (2) describe the practical implications of reported dietary intakes to support the physical and dietary requirements of tactical personnel. This research will assist in understanding tactical personnel's free-living dietary intake and, through comparison to other available information (e.g., population normative data), support the development of evidence-based dietary interventions and recommendations.

\section{Materials and Methods}

This systematic review was conducted and reported following the Preferred Reporting Items for Systematic Reviews and Meta-analyses (PRISMA) protocol [32]. The protocol was prospectively registered with the International Prospective Register of Systematic Reviews (PROSPERO registration: CRD42021224080).

\subsection{Search Strategy}

Four electronic databases were searched, including Medline (via PubMed), EMBASE (via Ovid), Cumulative Index to Nursing and Allied Health Literature (CINAHL via EBSCOhost) and Web of Science. Publications were restricted to those published from 1990 up until 28 October 2020. No language restrictions were applied. A combination of keywords designed for PubMed were used and converted for other databases using CREBP-SRA Polyglot Search Translator [33]. For each database, converted keywords were checked for accuracy and modified as required. The entire search strategy can be seen in Table S1. Additional relevant studies were identified through forward and backward ('snowballing') citation searching [34].

\subsection{Eligibility Criteria}

To be eligible for inclusion, each study had to satisfy criteria regarding population, intervention, comparison, outcome, and study design (Table 1). Published studies involving tactical personnel (including military personnel, law enforcement personnel, fire and rescue personnel, and active-services personnel), aged $\geq 18$ years, and following a free-living diet (e.g., with no restrictions and no food provided) were included. Studies that failed to report on any outcomes of interest. were excluded as were studies with interventions centred on 
dietary supplementation of macronutrients or diets for special training or altitude, as these impact dietary requirements and may not reflect usual free-living macronutrient intake.

Table 1. Eligibility criteria for each domain for a systematic review of studies reporting dietary intake in tactical personnel, according to the Preferred Reporting Items for Systematic Reviews and Meta-Analyses framework [32].

\begin{tabular}{|c|c|c|}
\hline Domain & Inclusion Criteria & Exclusion Criteria \\
\hline Population & $\begin{array}{l}\text { Tactical personnel (including military personnel, law } \\
\text { enforcement personnel, fire and rescue personnel, and } \\
\text { active-services personnel), } \geq 18 \text { years, that are } \\
\text { active-services personnel (full time or part time) }\end{array}$ & $\begin{array}{l}\text { Tactical personnel with medical conditions or } \\
\text { medications that influence metabolism or nutrition } \\
\text { requirements, pregnant women, and disabled active } \\
\text { services personnel }\end{array}$ \\
\hline Intervention & $\begin{array}{l}\text { Participants following a free-living diet with no } \\
\text { restrictions or food provided }\end{array}$ & $\begin{array}{l}\text { Dietary supplementation } \\
\text { Diets for special training or altitude } \\
\text { Food provided to participants }\end{array}$ \\
\hline Comparison & No comparison groups required & \\
\hline Outcomes & $\begin{array}{l}\text { The primary outcomes include dietary intake of } \\
\text { energy, carbohydrate, protein and/or fat }\end{array}$ & No outcomes of interest reported. \\
\hline Study design & $\begin{array}{l}\text { Original research published from } 1990 \text { up until } \\
\text { 28 October } 2020\end{array}$ & $\begin{array}{l}\text { Conference papers, dissertations, abstracts without full } \\
\text { text, and protocol papers where we were unable to } \\
\text { identify a published result paper. }\end{array}$ \\
\hline
\end{tabular}

\subsection{Study Screening}

Duplicate records identified during the search strategy were removed using Endnote (version 9) [35]. Initially, records were identified and marked as ineligible and excluded via text-mining in Endnote by identifying keywords not relevant to this review (e.g., children and animal studies) [36]. Two authors (AT and KL) conducted the title and abstract screening for eligibility in Covidence a web-based, review management, software platform [37], with conflict resolution was completed by a third author (KMS). The full texts of potentially eligible papers were reviewed to confirm eligibility by two independent investigators (AT and KL). Disagreements were managed by consensus or a third reviewer when required (KMS). One publication in a language other than English was transcribed using Google Translate ${ }^{\circledR}$ before the full-text screening [38].

\subsection{Data Extraction}

The primary outcome of this review was dietary intake including energy, carbohydrate, protein, and fat. Data from the included studies were extracted into an electronic spreadsheet by two authors (AT and CW) and checked for accuracy by two separate authors (KMS and KL). Items extracted included study details (author, publication date, country, study design, setting), participant characteristics (age, sex, height, weight, body mass index), and key methodologies and assessment tools. Data were extracted for baseline, preintervention, or pre-deployment data. If a study did not report body mass index yet height and weight data was available, BMI was calculated using the formula BMI $=\mathrm{kg} / \mathrm{m}^{2}$ where $\mathrm{kg}$ is a person's weight in kilograms and $\mathrm{m}^{2}$ is their height in meters squared. Dietary data were converted to the same units used in the military dietary reference intakes (MDRI) for comparison. Dietary intake was reported in kcal, protein in grams, and carbohydrate and fat intake as percentage of energy intake. As required, kilojoules were converted to kcal and grams or kcal were converted to \% total energy. If studies stratified participants, the Cochrane formula for 'combined groups of means and standard deviations into a single group' was used [39]. The analytical approach used narrative description that reported dietary intake of energy, carbohydrate, protein and fat, occupation of participants, and outcomes of the study.

\subsection{The Military Dietary Reference Intakes (MDRIs)}

The reported dietary intake of energy, carbohydrate, protein, and fat in included studies were compared to the military dietary reference intakes (MDRIs) [31]. The reference 
intakes were adapted from the sex- and age-specific recommended daily allowances (RDAs). The RDAs are the nutrient standards intended to meet the requirements of majority of healthy Americans aged $\geq 2$ years [40]. While these guidelines may not be applicable to some international tactical personnel, these were the only broadly applicable guidelines in international scholarly literature.

\subsection{Quality Assessment}

The Academy of Nutrition and Dietetics Quality Criteria Checklist (QCC) for primary research from the Academy of Nutrition and Dietetics Evidence Analysis Manual [41], was used to assess study quality. The QCC includes ten validity questions based on the Agency for Healthcare Research and Quality domains for research studies. It evaluates whether studies addressed selection, bias, generalizability, data collection, and analysis to a sufficient standard in their reporting. Occasionally, a major question is not applicable (N/A) to a specific study. For example, the use of N/A is indicated in validity question 3 of the checklist which looks at "were study groups comparable or was an appropriate reference standard used" when only one group was studied, with no comparison group. Two investigators independently completed the assessment of study quality (AT and KL). Disagreements were managed by consensus. Studies were given an overall rating as "positive", "negative" or "neutral". No studies were excluded based on the overall quality rating.

\section{Results}

\subsection{Search Results}

A total of 18,578 records were identified through database searches (Figure 1). After duplicates were removed, 8310 records remained for title and abstract screening. Overall, 158 studies were identified by the primary search and one study through forward/backward citation searching resulting in 159 studies being reviewed in full text. Of these studies an additional 137 were excluded due to the population $(n=5)$, intervention $(n=19)$, outcomes $(n=73)$, and study design $(n=40)$ not meeting inclusion criteria. A total of 22 studies were included for this review.

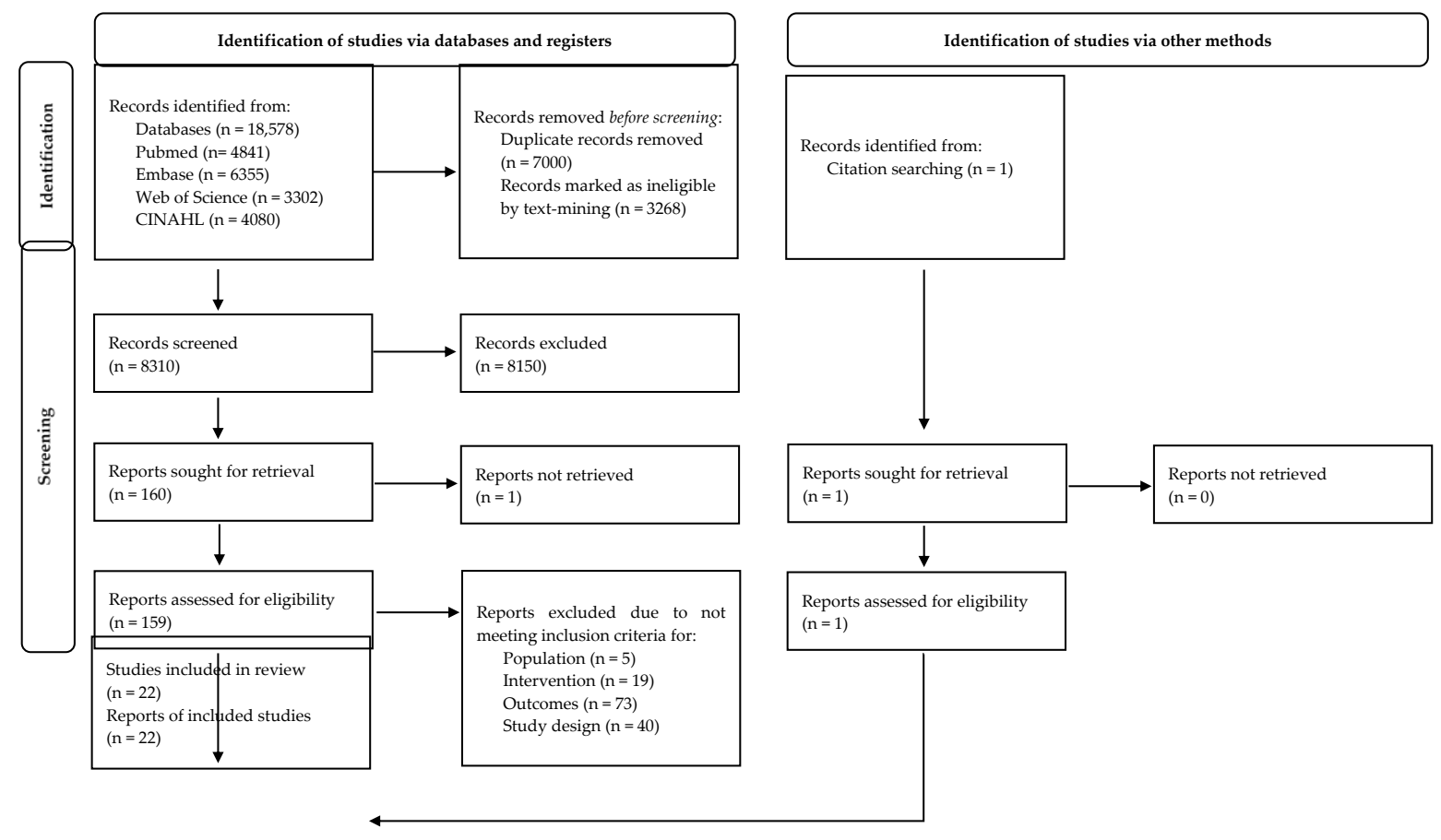

Figure 1. Preferred Reporting Items for Systematic Reviews and Meta-Analysis flowchart of the search results and the included studies. 


\subsection{Study and Sample Characteristics}

Characteristics of included studies can be seen in Table 2. All included studies were published between 1990 and 2020. They involved military personnel $(n=16)$ [42-57], law enforcement personnel $(n=4)[26,58-60]$, or firefighters $(n=2)[61,62]$, and were from a range of countries, including the United States of America (USA) ( $n=9)[26,42-44,50-52,54,62]$, Israel $(\mathrm{n}=3)[46,47,57]$, the United Kingdom $(\mathrm{UK})(\mathrm{n}=2)$ [53,59], Italy [55], Belgium [48], Brazil [58], Canada [60], Cameroon [49], Thailand [45], Iran [56], and Australia [61] ( $\mathrm{n}=1)$.

Table 2. Study and sample characteristics of included studies $(\mathrm{N}=22$; Mean $\pm \mathrm{SD})$.

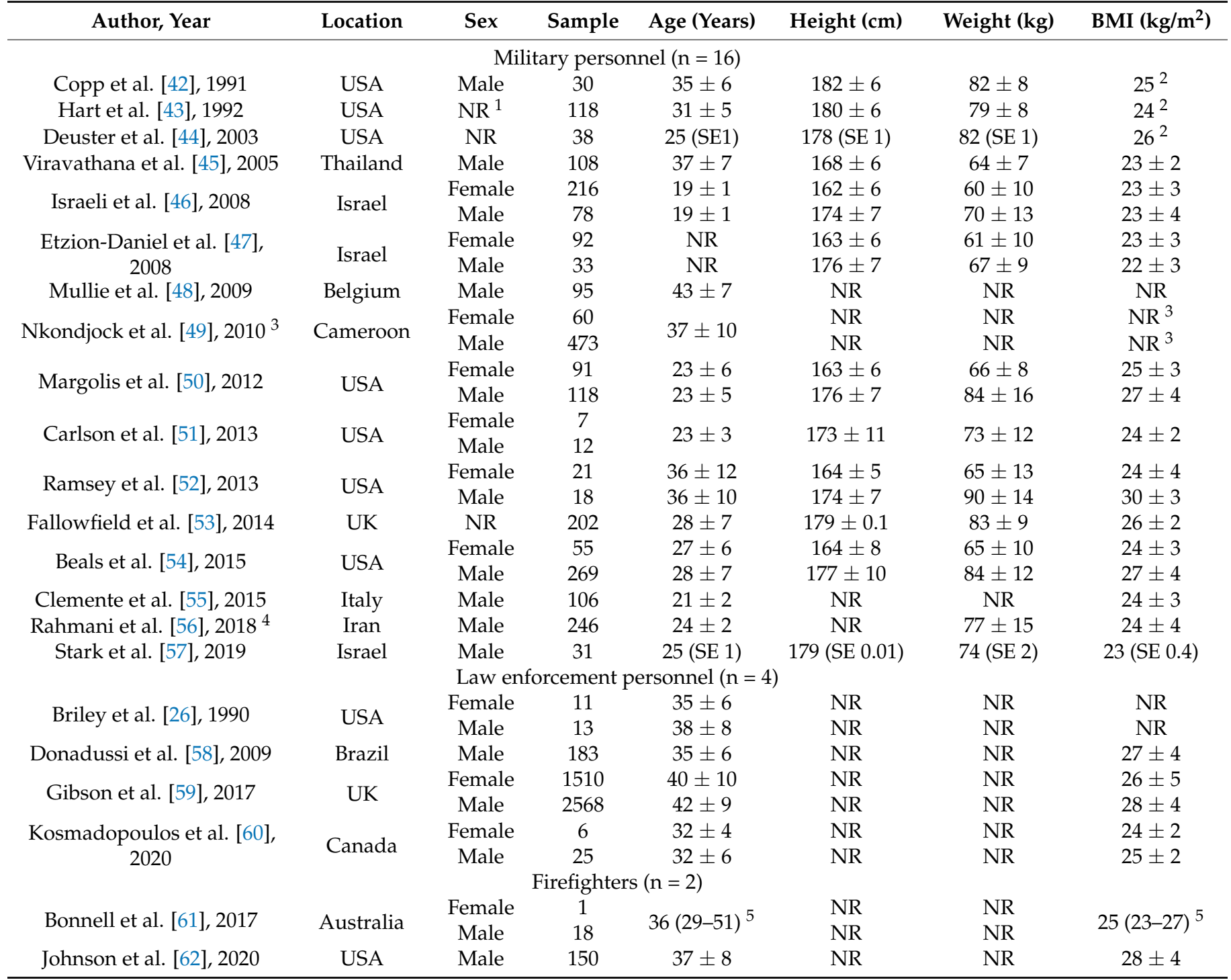

Abbreviations: BMI, body mass index; SE, standard error; USA, United States of America; UK, United Kingdom; ${ }^{1} \mathrm{NR}=$ not reported; not reported in the manuscript; ${ }^{2}$ BMI was calculated from reported height and weight values. The formula is BMI $=\mathrm{kg} / \mathrm{m}^{2} \mathrm{where} \mathrm{kg}$ is a person's weight in kilograms and $\mathrm{m}^{2}$ is their height in meters squared; ${ }^{3}$ Nkondjock et al. [49], reported BMI across three strata however, the sample size per each strata is not reported to combine means and standard deviations; ${ }^{4}$ Rahmani et al. [56], stratified participants into four groups based on Quartiles of AHEI-2010. Combined groups of means and Standard deviations into a single group by Cochrane's formula; ${ }^{5}$ Bonnell et al. [61], reported age and body mass index as median (IQR).

Most studies reported both male and female data [26,46,47,49-51,54,59-61], eight included male data only $[42,45,48,55-58,62]$, and three did not specify sex $[43,44,53]$. Sample sizes ranged from 19 to 4078 participants. The mean age of participants in the included studies ranged from $19( \pm 1)$ to $43( \pm 7)$ years (Table 2$)$. BMI was reported in 16 studies [45-47,50-62], was able to be calculated in three studies [42-44], and was not re- 
ported or able to be calculated in three studies $[26,48,49]$. Available BMI data for females ranged from $23( \pm 3)$ to $26( \pm 5) \mathrm{kg} / \mathrm{m}^{2}$ and males ranged from $22( \pm 4)$ to $30( \pm 3) \mathrm{kg} / \mathrm{m}^{2}$ (Table 2).

Methods for dietary assessment used in the included studies include food frequency checklist or questionnaire [42,44,46-51,55,56,62], 24 h recall [42,54,57,58,61], 3-day food record [43,45], 4-day food record [48,53], 7-day food record [26,59], various nutrition and lifestyle questionnaires $[49,52,54]$, and photographs of food $[58,60]$.

Almost one third of included studies did not compare dietary intakes with a dietary reference guideline $(n=7)[43,48,50,55,58,59,61]$. Of those that did, four strictly used the MDRIs [47,52,53,57] Two studies used a combination of MDRI with sports nutrition guidelines [54], and Dietary guidelines for Americans (DRAs) [44]. Alternate reference guidelines included Institute of Medicines dietary reference intakes (DRIs) ( $n=4)[46,51,60,62]$, U.S. Dietary Goals $(n=2)[26,42]$, Department of agriculture's dietary guidelines $(n=2)[49,51]$, International Network of Food Data Systems [49], Alternative Healthy Eating Index2010 [56], Dietary Reference Intake for Thais [45], Military recommended dietary allowances (MRDA), and Safe and adequate daily dietary intakes (ESADDI) according to military Nutrition Allowances, Standards, and Education $(n=1)$ [42].

\subsection{Reported Dietary Intakes}

All included studies assessed the energy intake of participants. Regardless of sex, all participants were below the MDRI for total energy intake (Table 3).

The majority of studies, except for two [49,58], assessed protein intake ( $\mathrm{n}=20,91 \%)$. Eleven studies, involving military personnel, reported male specific results with the majority $(\mathrm{n}=8,73 \%$ ) exceeding the MDRI of $91 \mathrm{~g} /$ day $[42,46,48,52,54,55,57]$. Three studies reported participants consuming $<91 \mathrm{~g} /$ day $(\mathrm{n}=3,27 \%)[45,47,50]$. One study involving law enforcement personnel reported males mostly meeting the MDRI with $90 \mathrm{~g} /$ day [59] and one study involving firefighters reported males exceeding the MDRI with $123 \mathrm{~g} /$ day [62]. Five studies involving military personnel reported female specific results with the majority exceeding the MDRI of $72 \mathrm{~g} /$ day $(\mathrm{n}=4,80 \%$ ) $[46,47,52,54]$, and one study consuming $<72 \mathrm{~g} /$ day [50]. One study involving law enforcement personnel reported females mostly meeting the MDRI with $71 \mathrm{~g} /$ day (99\% of the MDRI) [59].

The majority of studies assessed carbohydrate intake ( $n=20,91 \%)$ except for two [49,58]. Eleven studies, involving military personnel, reported male specific results with the majority $(n=10,91 \%)$ finding participants below the MDRI of $\geq 55 \%$ of total energy [42,45-48,50,52,54,56,57], and one study reported males meeting the MDRI with $56 \%$ of total energy from carbohydrates [55]. One study involving law enforcement personnel [59], and one involving firefighters [62], reported males were below the MDRI for carbohydrates. Five studies involving military personnel reported female specific results and they were all below the MDRI of $\geq 55 \%$ of total energy $[46,47,50,52,54]$. As was the one study with female law enforcement personnel [59].

All but one study [49], assessed fat intake $(n=21,95 \%)$. Eleven studies, involving military personnel, reported male specific results with the majority ( $n=8,73 \%$ ) exceeding the MDRI of $\leq 30 \%$ of total energy $[42,46-50,52,54,57]$, with the remaining three studies meeting the MDRI $(n=3,27 \%)[45,55,56]$. Two studies involved male law enforcement personnel [58,59], and one study involved male firefighters [62], and these studies likewise reported results above the MDRI. Five studies, involving military personnel, reported female specific results with the majority $(n=4,80 \%)$ exceeding the MDRI of $\leq 30 \%$ of total energy $[46,47,50,52]$, and one study below the MDRI with $29 \%$ of total energy from fat. The one study with female law enforcement personnel reported participants exceeding the MDRI [59]. 
Table 3. Reported energy and macronutrient intakes of female and male tactical personnel in the included studies $(\mathrm{N}=22)$.

\begin{tabular}{|c|c|c|c|c|c|c|c|c|c|}
\hline Author, Year & Sex & $\begin{array}{l}\text { Energy } \\
\text { kcal/day }\end{array}$ & $\begin{array}{c}\text { Compared to } \\
\text { MDRI: } \mathrm{F}=2300 \\
\mathrm{kcal} / \mathrm{d} \\
\mathrm{M}=3250 \mathrm{kcal} / \mathrm{d}\end{array}$ & Protein g/day & $\begin{array}{l}\text { Compared to } \\
\text { MDRI: } \\
F=72 \text { g/day } \\
M=91 \text { g/day }\end{array}$ & $\begin{array}{l}\text { Carbohydrate } \\
\% \text { of Energy }\end{array}$ & $\begin{array}{l}\text { Compared to } \\
\text { MDRI: } \\
\geq 55 \% \text { Total } \\
\text { Energy }\end{array}$ & $\begin{array}{c}\text { Fat } \\
\% \text { of Energy }\end{array}$ & $\begin{array}{l}\text { Compared to } \\
\text { MDRI: } \\
\leq 30 \% \text { Total } \\
\text { Energy }\end{array}$ \\
\hline \multicolumn{10}{|c|}{ Military personnel $(\mathrm{n}=16)$} \\
\hline Copp et al. [42], 1991 & Male & $2585 \pm 776$ & $80 \%$ of MDRI & $103^{2}$ & $113 \%$ of MDRI & $48 \pm 9$ & Below MDRI & $34 \pm 10$ & Above MDRI \\
\hline Hart et al. [43], 1992 & $\mathrm{NR}^{1}$ & $2729 \pm 803$ & - & $102^{2}$ & - & $45 \pm 8$ & Below MDRI & $34 \pm 6$ & Above MDRI \\
\hline Deuster et al. [44], 2003 & NR & 2962 (SE 239) & - & 135 (SE 14) & - & $41^{2}$ & Below MDRI & $38^{2}$ & Above MDRI \\
\hline Viravathana et al. [45], 2005 & Male & $2304 \pm 645$ & $71 \%$ of MDRI & $81 \pm 25$ & $89 \%$ of MDRI & $53 \pm 9$ & Below MDRI & $30 \pm 7$ & Meeting MDRI \\
\hline Israeli et al. [46], 2008 & Male & $2656 \pm 1068$ & $82 \%$ of MDRI & $106 \pm 47$ & $116 \%$ of MDRI & $50^{2}$ & Below MDRI & $33^{2}$ & Above MDRI \\
\hline \multirow{2}{*}{ Etzion-Daniel et al. [47], 2008} & Female & $1993 \pm 736$ & $87 \%$ of MDRI & $87 \pm 34$ & $121 \%$ of MDRI & $53^{2}$ & Below MDRI & $34^{2}$ & Above MDRI \\
\hline & Male & $2368 \pm 723$ & $73 \%$ of MDRI & $88 \pm 31$ & $97 \%$ of MDRI & $52^{2}$ & Below MDRI & $34^{2}$ & Above MDRI \\
\hline Mullie et al. [48], $2009^{3}$ & Male & $3100 \pm 1079$ & $95 \%$ of MDRI & $119 \pm 37$ & $131 \%$ of MDRI & $42 \pm 7$ & Below MDRI & $37 \pm 8$ & Above MDRI \\
\hline \multirow{2}{*}{ Nkondjock et al. [49], $2010^{4}$} & Female & $1852 \pm 1356$ & $81 \%$ of MDRI & NR & - & NR & - & NR & - \\
\hline & Male & $2052 \pm 1356$ & $63 \%$ of MDRI & NR & - & NR & - & NR & - \\
\hline \multirow{2}{*}{ Margolis et al. [50], 2012} & Female & $1824 \pm 1014$ & $79 \%$ of MDRI & $69 \pm 38$ & $96 \%$ of MDRI & $49^{2}$ & Below MDRI & $36^{2}$ & Above MDRI \\
\hline & Male & $1975 \pm 909$ & $61 \%$ of MDRI & $78 \pm 36$ & $86 \%$ of MDRI & $49^{2}$ & Below MDRI & $35^{2}$ & Above MDRI \\
\hline Carlson et al. [51], 2013 & $\mathrm{NR}^{5}$ & $3231 \pm 2215$ & - & $117 \pm 90$ & - & $51^{2}$ & Below MDRI & $33^{2}$ & Above MDRI \\
\hline Ramsey et al. [52], 2013 & Male & $2639 \pm 1252$ & $81 \%$ of MDRI & $100 \pm 51$ & $110 \%$ of MDRI & $44^{2}$ & Below MDRI & $33^{2}$ & Above MDRI \\
\hline Fallowfield et al. [20], 2014 & NR & $3173+854^{2}$ & - & $127^{2}$ & - & $46 \pm 7$ & Below MDRI & $35 \pm 6$ & Above MDRI \\
\hline \multirow{2}{*}{ Beals et al. [54], 2015} & Female & $1920 \pm 956$ & $83 \%$ of MDRI & $84 \pm 47$ & $116 \%$ of MDRI & $53^{2}$ & Below MDRI & $29 \pm 9$ & Meeting MDRI \\
\hline & Male & $2574 \pm 974$ & $79 \%$ of MDRI & $116 \pm 56$ & $127 \%$ of MDRI & $49^{2}$ & Below MDRI & $32 \pm 10$ & Above MDRI \\
\hline Clemente et al. [55], $2015^{6}$ & Male & $3071 \pm 737$ & $94 \%$ of MDRI & $120 \pm 30$ & $132 \%$ of MDRI & $56^{2}$ & Meeting MDRI & $28^{2}$ & Meeting MDRI \\
\hline Rahmani et al. [56], $2018^{7}$ & Male & $2232 \pm 504$ & $69 \%$ of MDRI & $104 \pm 21$ & $114 \%$ of MDRI & $49^{2}$ & Below MDRI & $30^{2}$ & Meeting MDRI \\
\hline Stark et al. [57], 2019 & Male & 2657 (SE 168) & $82 \%$ of MDRI & 113 (SE 9) & $124 \%$ of MDRI & $47^{2}$ & Below MDRI & $36^{2}$ & Above MDRI \\
\hline
\end{tabular}


Table 3. Cont.

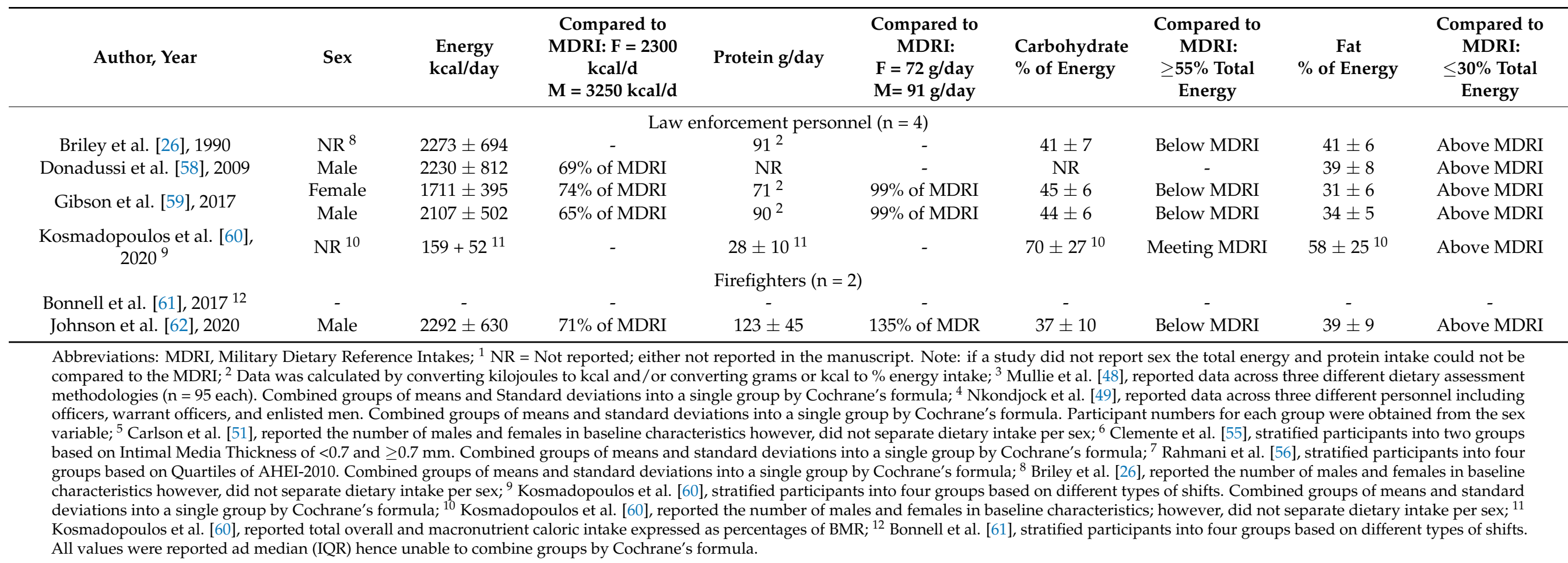




\subsection{Quality Assessment}

Of the 22 studies, 16 were rated as positive and six were rated as neutral as per the Academy of Nutrition and Dietetics Quality Criteria Checklist. The critical appraisal results can be seen in Table S2. Of the studies that were graded neutral the most common domain impacting the studies' scores were their lack of describing the handling of withdrawals, followed by reported dietary intake cannot be comparable due to not presenting means and standard deviations, their statistical analysis was not mentioned in detail, and/or their limitations were not discuss in detail. For Nkondjock et al. [49], reported energy and macronutrient intakes were stratified across three different personnel including officers, warrant officers, and enlisted men however, tabulated participant numbers were inconsistent with those reported in the body of text.

\section{Discussion}

This systematic review aimed to: (1) describe the reported free-living dietary intake (energy and macronutrients) of tactical personnel including military, law enforcement, and fire and rescue, and (2) describe the practical implications of reported dietary intakes to support the physical and dietary requirements of tactical personnel. The volume of evidence from the reported studies suggest that, comparatively to the MDRI, tactical personnel met dietary protein and exceeded dietary fat recommendations but failed to meet energy and carbohydrate recommendations. Similarly, a recent systematic review conducted in athletes who like some tactical personnel perform regular training, reported that team-sport athletes met or exceeded recommendations for protein and/or fat but did not meet energy and carbohydrate recommendations [63]. This, despite these athletes having access to high-quality research studies and up-to-date consensus dietary guidelines [63-65].

\subsection{Suboptimal Free-Living Energy and Carbohydrate Intake}

In comparison to the MDRI recommendations, free-living dietary energy and carbohydrate intake across military personnel, law enforcement personnel, and firefighters, failed to reach recommended values, regardless of sex. An appropriate dietary energy intake is important for tactical populations as their occupational activities can be physically demanding [66-68]. Inadequate energy intake can lead to weight loss, decreases in lean muscle mass, and decreases in bone density, which can affect daily performance, increase injury risk, and prolong recovery time [69]. Tactical occupations are renowned for phases of energy deficiency and recovery, and a potential risk for Relative Energy Deficiency in Sport (RED-S) syndrome in military personnel has previously been reported [69]. Therefore, while the reported BMI of tactical personnel did not support a chronic energy deficiency as they were all $>25 \mathrm{~kg} / \mathrm{m}^{2}$ (e.g., categorized as normal through to obese), it is unclear whether higher BMI values are reflective of increased lean (muscle) mass or fat mass. Some tactical occupations personnel exhibit higher levels of physical activity and/or strength training while others may intermittently be active or be relatively sedentary [70,71]. Studies describing the physical activity levels of tactical personnel can help advise specific dietary recommendations [72]. Several studies have documented tactical personnel's physical fitness is associated with their diet and nutrition status [73-75]. Of course suboptimal energy intakes may reflect under-reporting, despite this, it is unclear whether suboptimal energy intakes may be reported by some tactical personnel due to a culture surrounding lean body composition goals and/or restricted dietary intake in these occupations. Previous studies have shown these trends in athletes [76,77], and we have recently reported high uptakes of special diets in law enforcement personnel including low carbohydrate, low fat, and other potentially restrictive diets [20], which may extend to other tactical occupations.

A systematic review of shift workers' dietary intake has previously described unconventional meal patterns, skipping meals, and consuming more food at 'unconventional' times [78]. For example, it is common in shift workers to see periods of fasting followed by excessive dietary intake (e.g., through the use of convenience or take-away foods, that are high in energy, fat and sugar) [78]. Copp et al., found military personnel skipped 
breakfast [42], and Rahmani et al., reported an inverse association between healthy eating and odds of depression and anxiety [56]. Based on the available evidence, while overall energy and carbohydrate intake appears to be suboptimal, further exploration on the freeliving type and timing of dietary energy and carbohydrate intake in tactical occupations is warranted [2].

\subsection{Excessive Free-Living Dietary Protein and Fat Intake}

Tactical personnel reported an adequate amount of dietary protein in comparison to the MDRI guidelines. Dietary protein intake supports a range of anabolic physiological functions including the synthesis of muscle proteins, hormones, enzymes, and antibodies. Adequate intake of protein can optimize occupational performance and insufficient protein intake can lead to protein catabolism, skeletal muscle weakness or wasting, illness, injuries, and longer recovery time [64,79].

Studies have repeatedly demonstrated that protein intake is adequate in the general population with some exceptions, (e.g., vegetarian, vegan and older populations [80-82]). However, the MDRI reference range is based around population recommendations (e.g., 0.8-1.5 g per kg body weight) but incorporates a higher upper level for enhanced physical activity or muscle mass accretion [31]. In addition, some studies have demonstrated lower protein intakes in night shift workers, alongside higher levels of snacking, so dietary adequacy may be impacted by work schedules and rostering [78]. While this systematic review has reported protein intakes that meet recommendations, it is plausible that targeted, quality protein intakes may be beneficial where there is low food availability to support nutrient intake and satiety, or for individuals undergoing regular resistance exercise [64,83].

Due to its popularity and potential benefits, dietary protein is commonly supplemented [84]. While only two of the studies specifically reported that participants were using protein or carbohydrate supplement food items (such as protein bars and protein powders [41,50]), it is possible that the use of these products is higher with a previous study reporting that approximately $40 \%$ of law enforcement personnel use protein supplements [20]. As protein supplements can be costly, can displace other foods and nutrients, and can potentially include other contaminants that may have side effects (e.g., added caffeine impacting alertness and sleep cycles), it is important that supplementation is considered within future dietary guidelines [64,84].

The majority of included studies reported fat intakes above the MDRI suggestion of being less than $30 \%$ of total energy intake. For the studies that were within this recommendation, the reported dietary fat intake was at the upper end of the recommended range. Excessive fat, particularly saturated fat, intake can cause health issues such as high LDL-cholesterol levels, increase cardiovascular disease (CVD) risk, and weight gain in tactical personnel [39]. This finding is of concern given the higher levels of obesity and BMI that has been reported in police [85], firefighters [86], and military personnel [87], when compared to the general population, and the association of these characteristics to CVD risk [88]. However, over two thirds of included studies ( $n=15,68 \%$ ) did not report saturated fat separately. Dietary patterns and behaviors that may contribute to higher fat intakes amongst tactical personnel include higher levels of snacking, high use of take-away foods, or a lower intake of fiber, fruit, or vegetables [20,78]. Similar to other active populations, tactical personnel may benefit from the inclusion of mono- and poly-unsaturated fat-based foods (e.g., fish, nuts, and seeds) to help meet energy requirements and provide anti-inflammatory benefits [31,63].

\subsection{Practical Implications and Priority Areas for Intervention}

Based on the volume of evidence presented in this review, priority areas for intervention programs and nutritional guidelines in tactical occupations should support (1) an adequate dietary energy and carbohydrate intake; (2) controlled dietary fat intake with consideration of population recommendations of reducing saturated fat and prioritizing unsaturated fat intake; and (3) moderate, high-quality protein intake that is not prioritized 
at the expense of other macronutrients. Where possible, nutrition professionals should interpret these recommendations to ensure they are food-based and are interpreted with consideration of tactical personnel's varied occupational demands. In addition, the consideration of other dietary factors including barriers to dietary intake and their solutions (e.g., healthy take-away options or convenience foods), dietary patterns and meal-timings, dietary support and/or environment and other practical recommendations may be beneficial to support these changes [20].

\subsection{Strengths and Limitations}

This systematic review found that tactical personnel in general exceeded protein recommendations. The studies also reported inadequate energy and carbohydrate intake and excessive fat intake of tactical participants in comparison to the MDRI. While included studies reflected the usual limitations of applied dietary research, (e.g., small sample sizes, heterogeneity of data, and the existence of under-reporting), the systematic review has pooled all available data to synthesize the best-available evidence. Due to the heterogeneity of studies, no meta-analysis or GRADE analysis were able to be conducted. While there was some representation across military and law enforcement personnel, there were limited studies across other tactical occupations (e.g., fire and rescue).

Interestingly, while this systematic review has provided some useful insights into the dietary intake of tactical personnel that can inform dietary interventions, it has not provided insight into the dietary patterns and meal timings of tactical personnel. These were largely unreported in the included studies; in part due to the common use of a food frequency questionnaire (FFQ) to estimate dietary intake in the included studies. This tool is useful in tactical occupations as they often do not readily support ease of recording through other methods (e.g., food or photo diary point-in-time assessments). While diet recall was used by several studies [42,54,57,58,61], and does not have this limitation, it is limited by recall bias [89]. High stress or unstructured environments or high use of convenience or takeaway foods may not support accurate recall or dietary timings. Like all studies that incorporate dietary assessment, under-reporting should be acknowledged and considered particularly when interpreting data that suggests under-consumption.

As they are designed for military personnel, future studies could inform an update of the current MDRI guidelines and, whether they are suitable to assess the dietary intake for all tactical personnel. In addition, guidelines that consider performance optimization, and therefore relevant sports and performance guidelines, may also be beneficial $[18,31,64,90]$. Large scale studies are also needed to identify the healthy eating barriers as this population face specific occupation-related barriers, such as shift work and working under extreme conditions [20]. Similarly, exploring RED-S or the long-term health effects of military occupations which incorporate phases of energy deficiency and recovery, characteristic of tactical occupations, is warranted [69].

Within this systematic review, sex was reported to varying levels and the authors did not receive any reply for raw data of the sex from the three papers with unspecified sex distributions. One publication was transcribed using Google Translate ${ }^{\circledR}$ and we acknowledge that extraction via this method is more prone to error than extraction of English language articles [38].

\section{Conclusions}

Based on the available evidence, tactical personnel, in general, met dietary protein and exceeded dietary fat recommendations but failed to meet energy and carbohydrate recommendations. Therefore, practical, and individualized approaches to support (1) an adequate, dietary energy and carbohydrate intake; (2) controlled dietary fat intake with consideration of population recommendations of reducing saturated fat and prioritizing unsaturated fat intake; and (3) moderate, high-quality protein intake that is not prioritized at the expense of other macronutrients; are warranted. 
Further research is needed to investigate nutrition interventions, dietary patterns, and barriers to dietary intake in tactical personnel. In addition, further consideration of updating national references guidelines for these occupations is warranted.

Supplementary Materials: The following are available online at https:/ /www.mdpi.com/article/10 $.3390 /$ nu13103502/s1, Table S1: Search strategy implemented across four electronic databases from 1990 up until 28 October 2020. Table S2: Quality assessment as per the Academy of Nutrition and Dietetics Quality Criteria Checklist.

Author Contributions: Conceptualization, K.L.M.-S. and R.M.O.; methodology, K.L.M.-S., A.V.T., K.W.L. and C.W.; software, A.V.T. and K.W.L.; validation, K.L.M.-S., C.W., G.R.C. and R.M.O.; formal analysis, A.V.T., K.W.L. and K.L.M.-S.; writing—original draft preparation, A.V.T. and K.W.L.; writing-review and editing, K.L.M.-S., A.V.T., K.W.L., C.W., R.M.O. and G.R.C.; supervision, K.L.M.S., R.M.O. and G.R.C.; project administration, K.L.M.-S. All authors have read and agreed to the published version of the manuscript.

Funding: This research received no external funding.

Institutional Review Board Statement: Not applicable.

Informed Consent Statement: Not applicable (systematic review).

Data Availability Statement: Data can be requested from the corresponding author.

Acknowledgments: The authorship team acknowledge Dianne Riedlinger, Skye Marshall and Hannah Mayer for their assistance in supporting the Master of Nutrition and Dietetics research students at Bond University, Gold Coast, Australia.

Conflicts of Interest: The authors declare no conflict of interest.

\section{References}

1. Hill, N.; Fallowfield, J.; Price, S.; Wilson, D. Military nutrition: Maintaining health and rebuilding injured tissue. Philos. Trans. R. Soc. B Biol. Sci. 2011, 366, 231-240. [CrossRef]

2. Maupin, D.; Schram, B.; Orr, R. Tracking Training Load and Its Implementation in Tactical Populations: A Narrative Review. Strength Cond. J. 2019, 41, 1-11. [CrossRef]

3. González, K.; Fuentes, J.; Márquez, J.L. Physical Inactivity, Sedentary Behavior and Chronic Diseases. Korean J. Fam. Med. 2017, 38, 111-115. [CrossRef] [PubMed]

4. Thorp, A.A.; Owen, N.; Neuhaus, M.; Dunstan, D.W. Sedentary Behaviors and Subsequent Health Outcomes in Adults: A Systematic Review of Longitudinal Studies, 1996-2011. Am. J. Prev. Med. 2011, 41, 207-215. [CrossRef]

5. Yang, L.; Cao, C.; Kantor, E.D.; Nguyen, L.; Zheng, X.; Park, Y.; Giovannucci, E.L.; Matthews, C.E.; Colditz, G.; Cao, Y. Trends in Sedentary Behavior Among the US Population, 2001-2016. JAMA 2019, 321, 1587-1597. [CrossRef] [PubMed]

6. Violanti, J.M.; Burchfiel, C.M.; Hartley, T.A.; Mnatsakanova, A.; Fekedulegn, D.; Andrew, M.E.; Charles, L.E.; Vila, B.J. Atypical work hours and metabolic syndrome among police officers. Arch. Environ. Occup. Health 2009, 64, 194-201. [CrossRef] [PubMed]

7. Violanti, J.M.; Burchfiel, C.M.; Miller, D.B.; Andrew, M.E.; Dorn, J.; Wactawski-Wende, J.; Beighley, C.M.; Pierino, K.; Joseph, P.N.; Vena, J.E.; et al. The Buffalo Cardio-Metabolic Occupational Police Stress (BCOPS) pilot study: Methods and participant characteristics. Ann. Epidemiol. 2006, 16, 148-156. [CrossRef]

8. Yoo, H.; Franke, W.D. Sleep Habits, Mental Health, and the Metabolic Syndrome in Law Enforcement Officers. J. Occup. Environ. Med. 2013, 55, 99-103. [CrossRef]

9. The Management of Overweight and Obesity Working Group. Va/dod Clinical Practice Guideline for Screening and Management of Overweight and Obesity; The Management of Overweight and Obesity Working Group: Washington, DC, USA, 2014.

10. Batt, S.; Geerlings, P.; Fetherston, C. Health characteristics and self-identified health promotion needs of Army personnel in Perth Western Australia. J. Mil. Veterans Health 2016, 24, 6.

11. Tomkinson, G.R.; Daniell, N.; Fulton, A.; Furnell, A. Time changes in the body dimensions of male Australian Army personnel between 1977 and 2012. Appl. Ergon. 2017, 58, 18-24. [CrossRef]

12. Violanti, J.M.; Fekedulegn, D.; Hartley, T.A.; Andrew, M.E.; Gu, J.K.; Burchfiel, C.M. Life expectancy in police officers: A comparison with the U.S. general population. Int. J. Emerg. Ment. Health Hum. Resil. 2013, 15, 217.

13. Bray, R.M.; Camlin, C.S.; Fairbank, J.A.; Dunteman, G.H.; Wheeless, S.C. The Effects of Stress on Job Functioning of Military Men and Women. Armed Forces Soc. 2001, 27, 397-417. [CrossRef] [PubMed]

14. Macmillan, F.; Karamacoska, D.; El Masri, A.; A McBride, K.; Steiner, G.; Cook, A.; Kolt, G.S.; Klupp, N.; George, E.S. A systematic review of health promotion intervention studies in the police force: Study characteristics, intervention design and impacts on health. Occup. Environ. Med. 2017, 74, 913-923. [CrossRef] 
15. Marks, A.N.; Sol, J.A.; Domitrovich, J.W.; West, M.R.; Ruby, B.C. Total Energy Intake and Self-Selected Macronutrient Distribution During Wildland Fire Suppression. Wilderness Environ. Med. 2020, 31, 188-196. [CrossRef] [PubMed]

16. Jahnke, S.A.; Poston, W.S.C.; Jitnarin, N.; Haddock, C.K. Health Concerns of the U.S. Fire Service: Perspectives from the Firehouse. Am. J. Health Promot. 2012, 27, 111-118. [CrossRef] [PubMed]

17. Gupta, C.C.; Coates, A.M.; Dorrian, J.; Banks, S. The factors influencing the eating behaviour of shiftworkers: What, when, where and why. Ind. Health 2019, 57, 419-453. [CrossRef] [PubMed]

18. Lowden, A.; Moreno, C.; Holmbäck, U.; Lennernäs, M.; Tucker, P. Eating and shift work—Effects on habits, metabolism and performance. Scand. J. Work Environ. Health 2010, 36, 150-162. [CrossRef] [PubMed]

19. Gibson, R.; Eriksen, R.; Singh, D.; Vergnaud, A.C.; Heard, A.; Chan, Q.; Frost, G. A cross-sectional investigation into the occupational and socio-demographic characteristics of British police force employees reporting a dietary pattern associated with cardiometabolic risk: Findings from the Airwave Health Monitoring Study. Eur. J. Nutr. 2017, 57, 2913-2926. [CrossRef]

20. MacKenzie-Shalders, K.; Matthews, C.; Dulla, J.; Orr, R. Law enforcement personnel are willing to change, but report influencing beliefs and barriers to optimised dietary intake. BMC Public Health 2020, 20, 1-9. [CrossRef]

21. Lockie, R.G.; Dawes, J.J.; Balfany, K.; Gonzales, C.E.; Beitzel, M.M.; Dulla, J.M.; Orr, R.M. Physical Fitness Characteristics That Relate to Work Sample Test Battery Performance in Law Enforcement Recruits. Int. J. Environ. Res. Public Health 2018, 15, 2477. [CrossRef]

22. Orr, R.; Pope, R.; Stierli, M.; Hinton, B. Grip Strength and Its Relationship to Police Recruit Task Performance and Injury Risk: A Retrospective Cohort Study. Int. J. Environ. Res. Public Health 2017, 14, 941. [CrossRef]

23. Genton, L.; Melzer, K.; Pichard, C. Energy and macronutrient requirements for physical fitness in exercising subjects. Clin. Nutr. 2010, 29, 413-423. [CrossRef]

24. Crombie, A.P.; Funderburk, L.K.; Smith, T.J.; McGraw, S.M.; Walker, L.A.; Champagne, C.M.; Allen, H.R.; Margolis, L.; McClung, H.L.; Young, A.J. Effects of Modified Foodservice Practices in Military Dining Facilities on Ad Libitum Nutritional Intake of US Army Soldiers. J. Acad. Nutr. Diet. 2013, 113, 920-927. [CrossRef]

25. Nykänen, T.; Pihlainen, K.; Santtila, M.; Vasankari, T.; Fogelholm, M.; Kyröläinen, H. Diet Macronutrient Composition, Physical Activity, and Body Composition in Soldiers During 6 Months Deployment. Mil. Med. 2018, 184, e231-e237. [CrossRef] [PubMed]

26. Briley, M.E.; Montgomery, D.H.; Blewett, J. Dietary intakes of police department employees in a wellness program. J. Am. Diet. Assoc. 1990, 90, 65-68. [CrossRef]

27. Mumford, E.A.; Taylor, B.G.; Kubu, B. Law Enforcement Officer Safety and Wellness Survey. PsycTESTS Dataset 2016, 18, 111-133.

28. Anibaldi, R.; Carins, J.; Rundle-Thiele, S. Eating Behaviors in Australian Military Personnel: Constructing a System of Interest for a Social Marketing Intervention. Soc. Mark. Q. 2020, 26, 229-243. [CrossRef]

29. Sotos-Prieto, M.; Cash, S.B.; Christophi, C.A.; Folta, S.; Moffatt, S.; Muegge, C.; Kales, S.N. Rationale and design of feeding America's bravest: Mediterranean diet-based intervention to change firefighters' eating habits and improve cardiovascular risk profiles. Contemp. Clin. Trials 2017, 61, 101-107. [CrossRef] [PubMed]

30. Booth, C. ADF Educators Guide to Healthy Eating (ADF EDGE); DSTO-GD-0727; Defence Science \& Technology Organisation: Scottsdale, TAS, Australia, 2013.

31. Headquarters Departments of the Army tN, and the Air Force. Army regulation 40-25. In Nutrition and Menu Standards for Human Performance Optimization; Headquarters Departments of the Army tN, and the Air Force: Washington, DC, USA, 2017.

32. Page, M.J.; E McKenzie, J.; Bossuyt, P.M.; Boutron, I.; Hoffmann, T.C.; Mulrow, C.D.; Shamseer, L.; Tetzlaff, J.M.; Moher, D. Updating guidance for reporting systematic reviews: Development of the PRISMA 2020 statement. J. Clin. Epidemiol. 2021, 134, 103-112. [CrossRef] [PubMed]

33. Clark, J.M.; Sanders, S.; Carter, M.; Honeyman, D.; Cleo, G.; Auld, Y.; Booth, D.; Condron, P.; Dalais, C.; Bateup, S.; et al. Improving the translation of search strategies using the Polyglot Search Translator: A randomized controlled trial. J. Med. Libr. Assoc. 2020, 108, 195-207. [CrossRef]

34. Briscoe, S.; Bethel, A.; Rogers, M. Conduct and reporting of citation searching in Cochrane systematic reviews: A cross-sectional study. Res. Synth. Methods 2019, 11, 169-180. [CrossRef]

35. The EndNote Team. EndNote; EndNote X9 Ed.; Clarivate: Philadelphia, PA, USA, 2013.

36. Usai, A.; Pironti, M.; Mital, M.; Mejri, C.A. Knowledge discovery out of text data: A systematic review via text mining. J. Knowl. Manag. 2018, 22, 1471-1488. [CrossRef]

37. Veritas Health Innovation. Covidence Systematic Review Software; Veritas Health Innovation: Melbourne, VIC, Australia.

38. Balk, E.M.; Chung, M.; Chen, M.L.; Trikalinos, T.A.; Kong Win Chang, L. Assessing the Accuracy of Google Translate to Allow Data Extraction from Trials Published in Non-English Languages; Agency for Healthcare Research and Quality (US): Rockville, MD, USA, 2013.

39. Higgins, J. Cochrane Handbook for Systematic Reviews of Interventions, Version 5.1.0 [updated March 2011]; The Cochrane Collaboration; Wiley-Blackwell: Chichester, UK, 2019.

40. Institute of Medicine. Dietary Reference Intakes Tables; The National Academies Press: Washington, DC, USA, 2006.

41. Academy of Nutrition and Dietetics. Evidence Analysis Manual: Steps in the Academy Evidence Analysis Process; Research International and Strategic Business Development Team, Ed.; Academy of Nutrition and Dietetics: Chicago, IL, USA, 2016.

42. Copp, E.K.; Green, N.R. Dietary intake and blood lipid profile survey of fighter pilots at Tyndall Air Force Base. Aviat. Space Environ. Med. 1991, 62, 837-841. [PubMed] 
43. Hart, S.; Morrison, C. Effect of age, family status, and physical activity on selected dietary components of TAC pilots. Mil. Med. 1992, 157, 397-401. [CrossRef]

44. Deuster, P.A.; Sridhar, A.; Becker, W.J.; Coll, R.; O’Brien, K.K.; Bathalon, G. Health assessment of U.S. Army Rangers. Mil. Med. 2003, 168, 57-62. [PubMed]

45. Viravathana, N.; Sirichakwal, P. Energy and nutrients intake of Thai active duty army personnel at the Army Special Warfare Command Unit. J. Med. Assoc. Thai. 2005, 88 (Suppl. S3), S110-S115.

46. Israeli, E.; Merkel, D.; Constantini, N.; Yanovich, R.; Evans, R.K.; Shahar, D.; Moran, D.S. Iron Deficiency and the Role of Nutrition among Female Military Recruits. Med. Sci. Sports Exerc. 2008, 40, S685-S690. [CrossRef]

47. Etzion-Daniel, Y.; Constantini, N.; Finestone, A.; Shahar, D.; Israeli, E.; Yanovich, R.; Moran, D.S. Nutrition Consumption of Female Combat Recruits in Army Basic Training. Med. Sci. Sports Exerc. 2008, 40, S677-S684. [CrossRef]

48. Mullie, P.; Clarys, P.; Hulens, M.; Vansant, G. (Margareta) Reproducibility and Validity of a Semiquantitative Food Frequency Questionnaire among Military Men. Mil. Med. 2009, 174, 852-856. [CrossRef]

49. Nkondjock, A.; Bizome, E. Dietary patterns associated with hypertension prevalence in the Cameroon defence forces. Eur. J. Clin. Nutr. 2010, 64, 1014-1021. [CrossRef] [PubMed]

50. Margolis, L.M.; Pasiakos, S.M.; Karl, J.P.; Rood, J.C.; Cable, S.J.; Williams, K.W.; Young, A.J.; McClung, J.P. Differential Effects of Military Training on Fat-Free Mass and Plasma Amino Acid Adaptations in Men and Women. Nutrients 2012, 4, 2035-2046. [CrossRef] [PubMed]

51. Carlson, A.R.; A Smith, M.; McCarthy, M.S. Diet, physical activity, and bone density in soldiers before and after deployment. U.S. Army Med. Dep. J. 2013, 2013, 25-30.

52. Ramsey, C.B.; Hostetler, C.; Andrews, A. Evaluating the Nutrition Intake of U.S. Military Service Members in Garrison. Mil. Med. 2013, 178, 1285-1290. [CrossRef] [PubMed]

53. Fallowfield, J.L.; Delves, S.K.; Hill, N.E.; Cobley, R.; Brown, P.; Lanham-New, S.A.; Frost, G.; Brett, S.J.; Murphy, K.; Montain, S.J.; et al. Energy expenditure, nutritional status, body composition and physical fitness of Royal Marines during a 6-month operational deployment in Afghanistan. Br. J. Nutr. 2014, 112, 821-829. [CrossRef] [PubMed]

54. Beals, K.; Darnell, M.E.; Lovalekar, M.; Baker, R.A.; Nagai, T.; San-Adams, T.; Wirt, L.M.D. Suboptimal Nutritional Characteristics in Male and Female Soldiers Compared to Sports Nutrition Guidelines. Mil. Med. 2015, 180, 1239-1246. [CrossRef]

55. Clemente, G.; Mancini, M.; Giacco, R.; Tornatore, A.; Ragucci, M.; Riccardi, G. Visceral adiposity and subclinical atherosclerosis in healthy young men. Int. J. Food Sci. Nutr. 2015, 66, 466-470. [CrossRef]

56. Rahmani, J.; Milajerdi, A.; Dorosty-Motlagh, A. Association of the Alternative Healthy Eating Index (AHEI-2010) with depression, stress and anxiety among Iranian military personnel. J. R. Army. Med. Corps 2018, 164, 87-91. [CrossRef]

57. Stark, A.H.; Weis, N.; Chapnik, L.; Barenboim, E.; Reifen, R. Dietary intake of pilots in the Israeli Air Force. Mil. Med. 2008, 173, 780-784. [CrossRef]

58. Donadussi, C.; Oliveira, A.F.; Fatel, E.C.D.; Dichi, J.B.; Dichi, I. Dietary fats and measures of adiposity in military policemen. Rev. Nutr. Braz. J. Nutr. 2009, 22, 847-855.

59. Gibson, R.; Eriksen, R.; Lamb, K.; McMeel, Y.; Vergnaud, A.-C.; Spear, J.; Aresu, M.; Chan, Q.; Elliott, P.; Frost, G. Dietary assessment of British police force employees: A description of diet record coding procedures and cross-sectional evaluation of dietary energy intake reporting (The Airwave Health Monitoring Study). BMJ Open 2017, 7, e012927. [CrossRef]

60. Kosmadopoulos, A.; Kervezee, L.; Boudreau, P.; Gonzales-Aste, F.; Vujovic, N.; Scheer, F.A.J.L.; Boivin, D.B. Effects of Shift Work on the Eating Behavior of Police Officers on Patrol. Nutrients 2020, 12, 999. [CrossRef] [PubMed]

61. Bonnell, E.K.; Huggins, C.E.; Huggins, C.T.; McCaffrey, T.A.; Palermo, C.; Bonham, M.P. Influences on Dietary Choices during Day versus Night Shift in Shift Workers: A Mixed Methods Study. Nutrients 2017, 9, 193. [CrossRef] [PubMed]

62. Johnson, B.V.; Mayer, J.M. Evaluating Nutrient Intake of Career Firefighters Compared to Military Dietary Reference Intakes. Nutrients 2020, 12, 1876. [CrossRef] [PubMed]

63. Jenner, S.L.; Buckley, G.L.; Belski, R.; Devlin, B.L.; Forsyth, A.K. Dietary Intakes of Professional and Semi-Professional Team Sport Athletes Do Not Meet Sport Nutrition Recommendations-A Systematic Literature Review. Nutrients 2019, 11, 1160. [CrossRef]

64. Kerksick, C.M.; Wilborn, C.D.; Roberts, M.D.; Smith-Ryan, A.; Kleiner, S.M.; Jäger, R.; Kreider, R.B. ISSN exercise \& sports nutrition review update: Research \& recommendations. J. Int. Soc. Sports Nutr. 2018, 15, 38.

65. Thomas, D.T.; Erdman, K.A.; Burke, L.M. American college of sports medicine joint position statement. Nutrition and athletic performance. Med. Sci. Sports Exerc. 2016, 48, 543-568.

66. Vila, B.D.K. Tired Cops: The Prevalence and Potential Consequences of Police Fatigue. Natl. Inst. Justice J. 2002, 16-21. [CrossRef]

67. Hem, E.; Ma, A.M.B.; Ekeberg, Ø. Suicide in Police-A Critical Review. Suicide Life-Threatening Behav. 2001, 31, 224-233. [CrossRef]

68. Rajaratnam, S.M.; Barger, L.K.; Lockley, S.W.; Shea, S.A.; Wang, W.; Landrigan, C.P.; Czeisler, C.A. Sleep disorders, health, and safety in police officers. JAMA 2011, 306, 2567-2578. [CrossRef]

69. O'Leary, T.J.; Wardle, S.L.; Greeves, J.P. Energy Deficiency in Soldiers: The Risk of the Athlete Triad and Relative Energy Deficiency in Sport Syndromes in the Military. Front. Nutr. 2020, 7, 142. [CrossRef]

70. Irving, S.; Orr, R.; Pope, R. Profiling the Occupational Tasks and Physical Conditioning of Specialist Police. Int. J. Exerc. Sci. 2019, $12,173-186$. 
71. Kukić, F.; Heinrich, K.M.; Koropanovski, N.; Poston, W.S.C.; Čvorović, A.; Dawes, J.J.; Orr, R.; Dopsaj, M. Differences in Body Composition across Police Occupations and Moderation Effects of Leisure Time Physical Activity. Int. J. Environ. Res. Public Health 2020, 17, 6825. [CrossRef]

72. Alemany, J.A.; Pierce, J.R.; Bornstein, D.B.; Grier, T.L.; Jones, B.H.; Glover, S.H. Comprehensive Physical Activity Assessment During U.S. Army Basic Combat Training. J. Strength Cond. Res. 2021. [CrossRef]

73. Tomczak, A.; Bertrandt, J.; Kłos, A.; Kłos, K. Influence of Military Training and Standardized Nutrition in Military Unit on Soldiers' Nutritional Status and Physical Fitness. J. Strength Cond. Res. 2016, 30, 2774-2780. [CrossRef]

74. Teixeira, C.S.; Pereira, E.F. Physical fitness, age and nutritional status of military personnel. Arq. Bras. Cardiol. 2010, 94, 438-443. [CrossRef] [PubMed]

75. Anyżewska, A.; Łakomy, R.; Lepionka, T.; Szarska, E.; Maculewicz, E.; Tomczak, A.; Bertrandt, J. Association Between Diet, Physical Activity and Body Mass Index, Fat Mass Index and Bone Mineral Density of Soldiers of the Polish Air Cavalry Units. Nutrients 2020, 12, 242. [CrossRef] [PubMed]

76. Jenner, S.L.; Trakman, G.; Coutts, A.; Kempton, T.; Ryan, S.; Forsyth, A.; Belski, R. Dietary intake of professional Australian football athletes surrounding body composition assessment. J. Int. Soc. Sports Nutr. 2018, 15, 43. [CrossRef] [PubMed]

77. Bradley, W.J.; Cavanagh, B.P.; Douglas, W.; Donovan, T.F.; Morton, J.P.; Close, G.L. Quantification of training load, energy intake, and physiological adaptations during a rugby preseason: A case study from an elite European rugby union squad. J. Strength Cond. Res. 2015, 29, 534-544. [CrossRef]

78. Souza, R.V.; Sarmento, R.A.; De Almeida, J.C.; Canuto, R. The effect of shift work on eating habits: A systematic review. Scand. J. Work. Environ. Health 2018, 45, 7-21. [CrossRef]

79. Beck, K.; Thomson, J.S.; Swift, R.J.; von Hurst, P.R. Role of nutrition in performance enhancement and postexercise recovery. Open Access J. Sports Med. 2015, 6, 259-267. [CrossRef]

80. Bakaloudi, D.R.; Halloran, A.; Rippin, H.L.; Oikonomidou, A.C.; Dardavesis, T.I.; Williams, J.; Wickramasinghe, K.; Breda, J.; Chourdakis, M. Intake and adequacy of the vegan diet. A systematic review of the evidence. Clin. Nutr. 2021, 40, 3503-3521. [CrossRef] [PubMed]

81. Mariotti, F.; Gardner, C.D. Dietary Protein and Amino Acids in Vegetarian Diets-A Review. Nutrients 2019, 11, 2661. [CrossRef]

82. Hengeveld, L.M.; Wijnhoven, H.; Olthof, M.R.; Brouwer, I.; Harris, T.B.; Kritchevsky, S.B.; Newman, A.B.; Visser, M.; for the Health ABC Study. Prospective associations of poor diet quality with long-term incidence of protein-energy malnutrition in community-dwelling older adults: The Health, Aging, and Body Composition (Health ABC) Study. Am. J. Clin. Nutr. 2018, 107, 155-164. [CrossRef]

83. MacKenzie-Shalders, K.L.; Byrne, N.; Slater, G.; King, N.A. The effect of a whey protein supplement dose on satiety and food intake in resistance training athletes. Appetite 2015, 92, 178-184. [CrossRef]

84. Maughan, R.J. Quality Assurance Issues in the Use of Dietary Supplements, with Special Reference to Protein Supplements. J. Nutr. 2012, 143, 1843S-1847S. [CrossRef]

85. Sörensen, L.; Smolander, J.; Louhevaara, V.; Korhonen, O.; Oja, P. Physical activity, fitness and body composition of Finnish police officers: A 15-year follow-up study. Occup. Med. 2000, 50, 3-10. [CrossRef]

86. Poston, W.S.; Haddock, C.K.; Jahnke, S.A.; Jitnarin, N.; Tuley, B.C.; Kales, S.N. The prevalence of overweight, obesity, and substandard fitness in a population-based firefighter cohort. J. Occup. Environ. Med. 2011, 53, 266-273. [CrossRef] [PubMed]

87. Defense Health Board. Implications of Trends in Obesity and Overweight for the Department of Defense. In Fit to Fight, Fit for Life; Department of Defense: Fall Church, VA, USA, 2013.

88. Thayyil, J.; Jayakrishnan, T.T.; Raja, M.; Cherumanalil, J.M. Metabolic syndrome and other cardiovascular risk factors among police officers. N. Am. J. Med. Sci. 2012, 4, 630-635. [CrossRef]

89. Black, A.E. Dietary assessment for sports dietetics. Nutr. Bull. 2001, 26, 29-42. [CrossRef]

90. Phillips, S.M. Dietary protein requirements and adaptive advantages in athletes. Br. J. Nutr. 2012, 108 (Suppl. S2), S158-S167. [CrossRef] 